\title{
Method for Identifying Stator and Rotor Faults of Induction Motors Based on Machine Vision
}

\author{
Lipeng Wei, ${ }^{1}$ Xiang Rong, ${ }^{1}$ Haibo Wang, ${ }^{1}$ Shuohang Yu, ${ }^{1}$ and Yang Zhang $\mathbb{D}^{2}$ \\ ${ }^{1}$ Tiandi (Changzhou) Automation Co., Ltd., Changzhou 213015, China \\ ${ }^{2}$ School of Electrical and Power Engineering, China University of Mining and Technology, Xuzhou 221116, China \\ Correspondence should be addressed to Yang Zhang; 2413810241@qq.com
}

Received 15 December 2020; Revised 1 January 2021; Accepted 9 January 2021; Published 22 January 2021

Academic Editor: Xiaodong Sun

Copyright (c) 2021 Lipeng Wei et al. This is an open access article distributed under the Creative Commons Attribution License, which permits unrestricted use, distribution, and reproduction in any medium, provided the original work is properly cited.

The detection results need to be analyzed and distinguished by professional technicians in the fault detection methods for induction motors based on signal processing and it is difficult to realize the automatic identification of stator and rotor faults. A method for identifying stator and rotor faults of induction motors based on machine vision is proposed to solve this problem. Firstly, Park's vector approach (PVA) is used to analyze the three-phase currents of the motor to obtain Park's vector ring (PVR). Then, the local binary patterns (LBP) and gray level cooccurrence matrix (GLCM) are combined to extract the image features of PVR. Finally, the vectors of image features are used as input and the types of induction motor faults are identified with the help of a random forest $(\mathrm{RF})$ classifier. The proposed method has achieved high identification accuracy in both the Maxwell simulation experiment and the actual motor experiment, which are $100 \%$ and $95.83 \%$, respectively.

\section{Introduction}

Induction motors (IMs) are currently one of the motors with the largest usage and widest application range $[1,2]$. As the main power unit of the industrial system, the health of IM will affect the normal operation of the entire system directly and even threaten personal safety. Therefore, it is very important to study motor control [3-5] and fault detection and identification methods. This paper mainly studies fault diagnosis methods, which have important theoretical significance and economic value for preventing major accidents, reducing excess maintenance, and improving production efficiency [6].

At present, the fault diagnosis methods of IM can be divided into three categories roughly, which are process modeling, signal processing, and artificial intelligence. The method based on process modeling usually establishes a mathematical model of faulty motor and converts the fault detection problem into the identification problem of corresponding parameters. For broken rotor bar (BRB) fault, the finite element method was used to establish IM models in [7-11] and the fault detection was realized by analyzing and comparing the changes of various physical quantities in the motor. The detection of BRB fault was realized by analyzing the changes of motor currents and gap flux density in [7]. The actual data and model data were compared to detect the BRB fault in $[8,9]$. The BRB fault detection was realized by monitoring the change of the external magnetic flux in [10]. The simulation results of motor models with stable and variable speed were compared and the speed oscillation was used for fault detection in [11]. A faulty IM model was established based on multiloop theory and the currents were analyzed to detect the BRB fault in [12]. For stator fault, a model with interturn short-circuit fault was established based on reference frame transformation theory and the fault detection was realized by analyzing the changes of currents, speed, and torque in $[13,14]$. The influence of the harmonics of the supply voltage was considered to establish a dynamic model with interturn short-circuit fault and the instantaneous power of the motor was used to detect the 
stator fault in [15]. The location parameters of interturn short-circuit fault were considered to establish a faulty model with any short-circuit coil and the fault was detected by analyzing the negative sequence components of the currents in [16].

The above fault detection methods of IM based on process modeling is relatively mature in theory, but it is difficult to obtain an accurate model of IM in practical applications, which affects the effect of fault detection. Therefore, the detection methods of stator and rotor faults based on signal processing have been proposed successively $[17,18]$ and the detection methods based on stator currents can be designed to be noninvasive, which have been widely studied and applied. The BRB fault of IM can make additional harmonic components at the frequencies of $(1 \pm 2 k s) f_{1}$ induce stator currents, where $k$ is the positive integer, $s$ is the slip of the motor, and $f_{1}$ is the supply frequency. These additional current components can be used as an indicator of BRB fault. The Kalman filter was used to eliminate the fundamental component of the current and the fault characteristics were highlighted to detect BRB fault in [19]. The Hilbert transform was used to convert the fundamental component of the current to a direct current component and the fault components were converted to the low-frequency components, which highlighted the characteristics of BRB fault in [20]. The multiple signal classification method was combined with the improved back-bone particle swarm optimization algorithm and empirical mode decomposition, respectively, to extract the characteristics of $\mathrm{BRB}$ fault accurately in $[21,22]$. The min-norm and least square methods were used to extract the frequencies and amplitudes of the fault components respectively and the online detection of BRB fault was realized in [23]. Park's vector approach (PVA) was used to display the fault components of the currents via graphics to detect BRB fault in [24] and PVA can also detect the interturn short-circuit fault. Park's vector modulus was combined with the Hilbert transform to extract the spectrum information of the currents and the detection of interturn short-circuit fault was realized in [25]. The square demodulation method of the stator currents was used to suppress the leakage of the fundamental component and the components of interturn short-circuit fault were highlighted to realize fault detection in [26]. The characteristics of the interturn short-circuit fault in the instantaneous active and reactive power were analyzed and the spectrum of instantaneous power was applied to the fault detection in [27]. The fast Fourier transform (FFT) was used to extract the spectrums of the three-phase currents and the standard deviation between the spectrums was calculated to eliminate the influence of the supply voltage imbalance in [28], which improved the detection accuracy of the interturn shortcircuit fault.

Although the above methods of fault detection based on signal processing have achieved excellent results, its detection results need to be analyzed and judged by humans, which requires high requirements for technicians on-site. In recent years, a variety of intelligent classification algorithms have been successfully used to identify motor faults automatically because of the rapid development of artificial intelligence. These methods usually use the way of datadriven to establish a diagnostic model, which can realize the classification and severity assessment of the motor faults. The stator voltages and currents were used as input vectors and the recognition of motor faults was realized by an artificial neural network in [29]. But the disadvantage is that the dimension of input vectors is too large and only the simulation experiment is completed. Then, in order to reduce the dimension of the feature vectors and improve the recognition rate of the motor faults, a large number of methods of feature extraction combined with intelligent classification algorithms were proposed. The envelopes of the stator currents were obtained by Hilbert transform and the fault frequencies and amplitudes in the envelopes were extracted by FFT, which were used as the input vectors of the multilayer perceptron to identify BRB fault at various operating states in [30]. The continuous wavelet transform was used to process the currents of interturn short-circuit fault with different degrees and the motor fault was recognized by feedback neural network based on dynamic learning rules in [31]. The wavelet transform was used to obtain the highfrequency energy layers of the stator currents and the stator fault was identified through Elman neural network in [32]. The multiple parameters such as the peak value and standard deviation of the currents were calculated as the input vectors of the support vector machine to identify multiple faults in [33]. The important information of the stator currents was extracted through information entropy and the fuzzy logic inference was used to recognize multiple faults in [34].

It can be seen from the principles of the above methods for fault identification based on artificial intelligence that such methods rely too much on measured data, especially fault data, which is difficult to satisfy in practical engineering applications. Based on the fault detection method by signal processing, this paper introduces machine vision to analyze and recognize the detection results to identify the interturn short-circuit and BRB faults of IM automatically.

This paper is organized as follows. Section 2 introduces the theoretical basis of PVA and discusses the difference of PVR, when the motor is healthy, with interturn short-circuit fault and BRB fault. Section 3 proposes a fault identification method of IM based on machine vision. Section 4 uses simulation and measured data to verify the effectiveness of the proposed fault identification method. Section 5 presents conclusions.

\section{Park's Vector Ring}

2.1. PVR of Healthy Motor. The PVA transforms the stator currents of the motor from the $(a, b, c)$ stationary coordinate system to the $(d, q)$ stationary coordinate system, and the current components $i_{d}, i_{q}$ in $d q$ coordinate constitute Park's vector components. As time goes by, PVR is formed in the $d q$ coordinate. The conversion relationship between $\left(i_{d}, i_{q}\right)$ and the three-phase currents $\left(i_{a}, i_{b}, i_{c}\right)$ is as follows: 


$$
\left\{\begin{array}{l}
i_{d}=\left(\frac{\sqrt{2}}{\sqrt{3}}\right) i_{a}-\left(\frac{1}{\sqrt{6}}\right) i_{b}-\left(\frac{1}{\sqrt{6}}\right) i_{c} \\
i_{q}=\left(\frac{1}{\sqrt{2}}\right) i_{b}-\left(\frac{1}{\sqrt{2}}\right) i_{c} .
\end{array}\right.
$$

Under ideal conditions, the three-phase currents are balanced with each other and have the following forms:

$$
\left\{\begin{array}{l}
i_{a}=I_{m} \cos \left(2 \pi f_{1} t+\varphi\right), \\
i_{b}=I_{m} \cos \left(2 \pi f_{1} t+\varphi-\frac{2 \pi}{3}\right), \\
i_{c}=I_{m} \cos \left(2 \pi f_{1} t+\varphi+\frac{2 \pi}{3}\right) .
\end{array}\right.
$$

Park's vector components at this time can be simplified as

$$
\left\{\begin{array}{l}
i_{d}=\left(\frac{\sqrt{6}}{2}\right) I_{m} \cos \left(2 \pi f_{1} t+\varphi\right) \\
i_{q}=\left(\frac{\sqrt{6}}{2}\right) I_{m} \sin \left(2 \pi f_{1} t+\varphi\right)
\end{array}\right.
$$

The following formula can be easily derived from equation (3):

$$
i_{d}^{2}+i_{q}^{2}=\frac{3 I_{m}^{2}}{2},
$$

where $t$ is the time variable and $I_{m}, f_{1}$, and $\varphi$ are the amplitude, fundamental frequency, and initial phase of the stator currents, respectively.

From equation (4), it can be seen that the PVR of the stator currents in the $(d, q)$ coordinate system under ideal conditions is a circle centered on the origin of the coordinate system, as shown in Figure 1. When the faults occur in IM, the three-phase currents are unbalanced, the currents contain harmonics caused by the faults, and the PVR will be no longer a circle. Based on this principle, the stator and rotor faults of IM can be detected. Therefore, the PVA is a graphical analysis method, which can show the characteristics of various motor faults in visual effects and has a good degree of discrimination.

2.2. PVR of Motor with Interturn Short-Circuit Fault. When the interturn short-circuit fault occurs in the stator winding of IM, the symmetry of the stator winding is destroyed and the gap flux generated by the stator winding becomes an ellipse, which can be decomposed into a forward rotation component and a reverse rotation component. The forward rotation component induces an alternating electric field at the frequency of $f_{1}$ in the stator winding; then, the positive sequence components are generated in the threephase currents. The reverse rotation component also induces an alternating electric field at frequency of $f_{1}$ in the stator

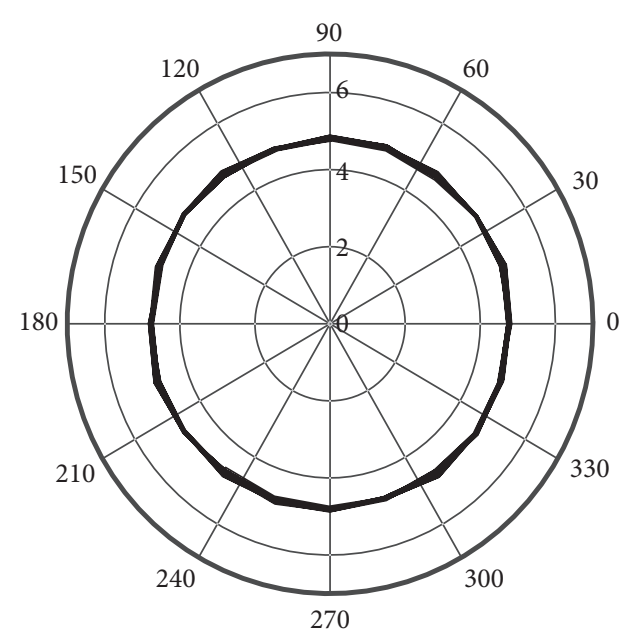

Figure 1: PVR of healthy IM.

winding, but the phase sequence is opposite to the previous one, so the negative sequence components are generated in the three-phase currents. Therefore, the expression of the stator currents of IM with interturn short-circuit fault is as follows:

$$
\left\{\begin{array}{l}
i_{a}=I_{m}^{+} \cos \left(2 \pi f_{1} t+\varphi^{+}\right)+I_{m}^{-} \cos \left(2 \pi f_{1} t+\varphi^{-}\right), \\
i_{b}=I_{m}^{+} \cos \left(2 \pi f_{1} t+\varphi^{+}-\frac{2 \pi}{3}\right)+I_{m}^{-} \cos \left(2 \pi f_{1} t+\varphi^{-}-\frac{2 \pi}{3}\right) \\
i_{c}=I_{m}^{+} \cos \left(2 \pi f_{1} t+\varphi^{+}+\frac{2 \pi}{3}\right)+I_{m}^{-} \cos \left(2 \pi f_{1} t+\varphi^{-}+\frac{2 \pi}{3}\right)
\end{array}\right.
$$

where $I_{m}^{+}, I_{m}^{-}, \varphi^{+}$, and $\varphi^{-}$are the amplitudes and initial phases of the three-phase positive and negative sequence currents, respectively. Park's vector components at this time are as follows:

$$
\left\{\begin{array}{l}
i_{d}=\left(\frac{\sqrt{6}}{2}\right)\left[I_{m}^{+} \cos \left(2 \pi f_{1} t+\varphi^{+}\right)+I_{m}^{-} \cos \left(2 \pi f_{1} t+\varphi^{-}\right)\right], \\
i_{q}=\left(\frac{\sqrt{6}}{2}\right)\left[I_{m}^{+} \cos \left(2 \pi f_{1} t+\varphi^{+}\right)-I_{m}^{-} \cos \left(2 \pi f_{1} t+\varphi^{-}\right)\right] .
\end{array}\right.
$$

From equation (6), it can be seen that when the interturn short-circuit fault occurs in the stator winding of IM, the amplitudes of Park's vector components are not equal due to the negative sequence components of the three-phase currents, which makes the PVR become an ellipse, as shown in Figure 2.

2.3. PVR of Motor with BRB Fault. When the BRB fault occurs in IM, a current component at the frequency of $(1-2 s) f_{1}$ is generated in the stator winding firstly. This current component works with the gap flux field to produce a torque that fluctuates at the frequency of $2 s f_{1}$, which generates the frequency components of $(1 \pm 2 s) f_{1}$ in the gap 


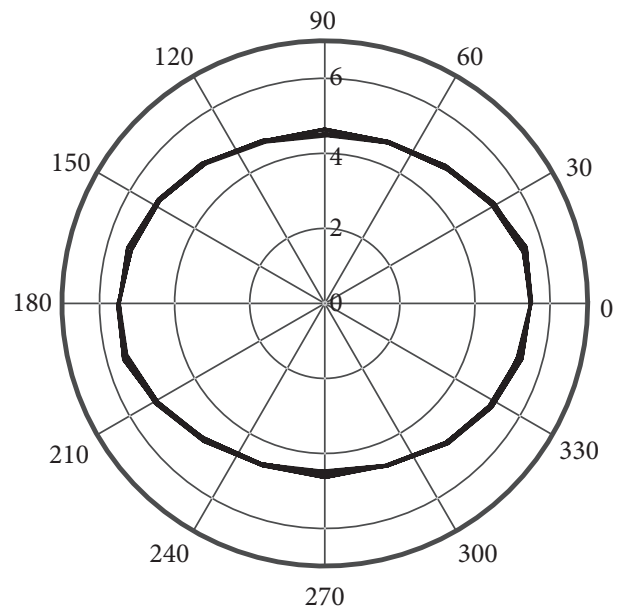

FIGURE 2: PVR of IM with interturn short-circuit fault.

flux field, so the $(1 \pm 2 s) f_{1}$ components will also be induced in the three-phase currents. At the same time, the $(1+2 s) f_{1}$ components in the three-phase currents will generate new torque fluctuation and then generate new current components, so the additional $(1 \pm 2 k s) f_{1}$ components will appear in three-phase currents when the rotor bar is broken. When

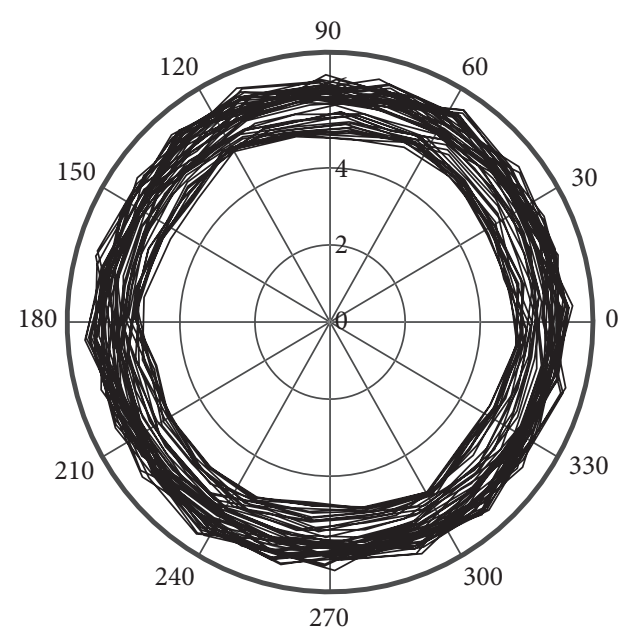

FIGURE 3: PVR of IM with BRB fault.

$k=1$, the amplitudes of the fault components are the largest. When the fault components of $k$ as other values are neglected, the expression of the three-phase currents of IM with BRB fault can be simplified as

$$
\left\{\begin{array}{l}
i_{a}=I_{m} \cos \left(2 \pi f_{1} t+\varphi\right)+I_{l} \cos \left(2 \pi(1-2 s) f_{1} t+\varphi_{l}\right)+I_{r} \cos \left(2 \pi(1+2 s) f_{1} t+\varphi_{r}\right), \\
i_{b}=I_{m} \cos \left(2 \pi f_{1} t-\frac{2 \pi}{3}+\varphi-\frac{2 \pi}{3}\right)+I_{l} \cos \left(2 \pi(1-2 s) f_{1} t+\varphi_{l}-\frac{2 \pi}{3}\right)+I_{r} \cos \left(2 \pi(1+2 s) f_{1} t+\varphi_{r}-\frac{2 \pi}{3}\right) \\
i_{c}=I_{m} \cos \left(2 \pi f_{1} t+\frac{2 \pi}{3}+\varphi+\frac{2 \pi}{3}\right)+I_{l} \cos \left(2 \pi(1-2 s) f_{1} t+\varphi_{l}+\frac{2 \pi}{3}\right)+I_{r} \cos \left(2 \pi(1+2 s) f_{1} t+\varphi_{r}+\frac{2 \pi}{3}\right)
\end{array},\right.
$$

where $I_{l}, I_{r}, \varphi_{l}$, and $\varphi_{r}$ are the amplitudes and initial phases of the BRB fault left sideband and right sideband components, respectively. Park's vector components at this time are as follows:

$$
\left\{\begin{array}{l}
i_{d}=\left(\frac{\sqrt{6}}{2}\right)\left[I_{m} \cos \left(2 \pi f_{1} t+\varphi\right)+I_{l} \cos \left(2 \pi(1-2 s) f_{1} t+\varphi_{l}\right)+I_{r} \cos \left(2 \pi(1+2 s) f_{1} t+\varphi_{r}\right)\right], \\
i_{q}=\left(\frac{\sqrt{6}}{2}\right)\left[I_{m} \sin \left(2 \pi f_{1} t+\varphi\right)+I_{l} \sin \left(2 \pi(1-2 s) f_{1} t+\varphi_{l}\right)+I_{r} \sin \left(2 \pi(1+2 s) f_{1} t+\varphi_{r}\right)\right] .
\end{array}\right.
$$

From equation (8), it can be seen that when the BRB fault occurs in IM, the amplitudes of Park's vector components are modulated by the harmonic components in the three-phase currents and the radius of the PVR fluctuates periodically, which makes the PVR become a ring, as shown in Figure 3.

\section{The Proposed Fault Identification Method}

In order to realize the intelligent diagnosis of the motor faults, this section proposes a fault identification method of
IM based on machine vision to solve the problem of manual analysis and identification of the detection results in the fault detection method based on signal processing. The specific process is shown in Figure 4.

Firstly, the three-phase currents of IM under various operating loads are collected and analyzed by PVA to form multiple sets of PVR. Then, the local binary patterns (LBP) and gray level cooccurrence matrix (GLCM) are used to extract the image features of PVR to reduce the data dimension and get feature vectors. Finally, part of the feature 


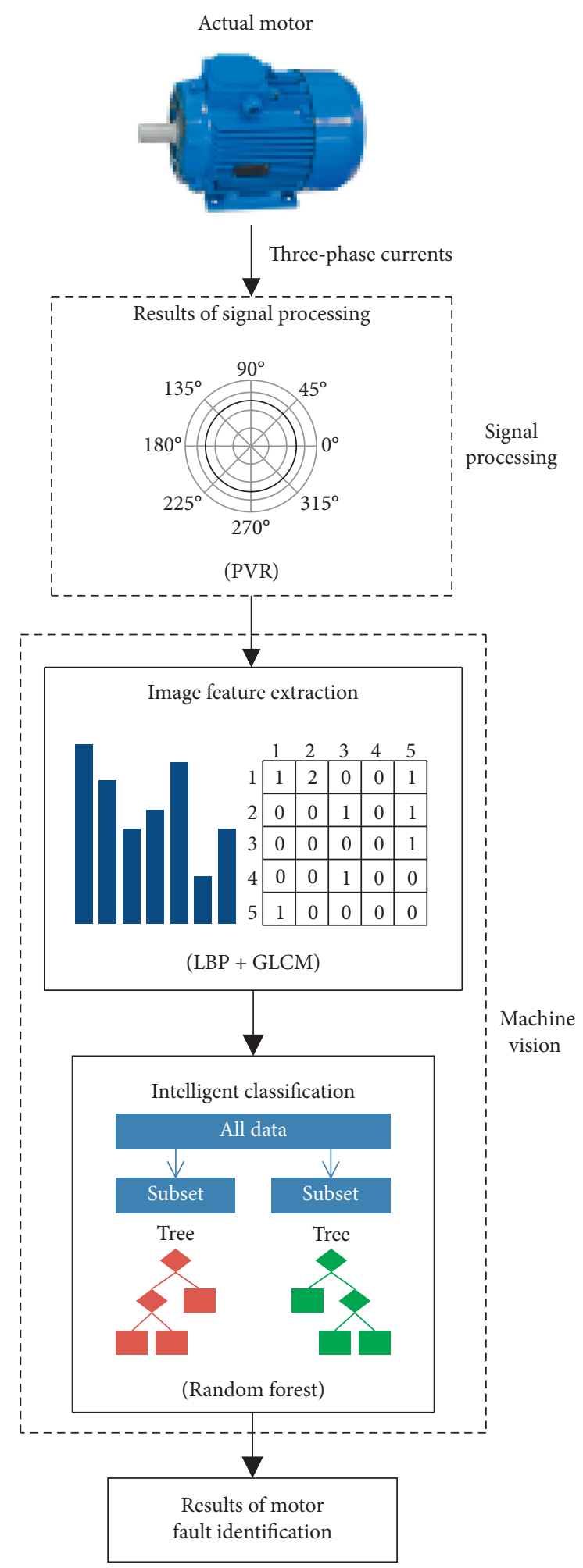

FIGURE 4: Motor fault identification method based on machine vision.

vectors of the PVR are selected as training data and the rest are used as test data and the motor fault types can be classified and identified automatically with the help of random forest $(\mathrm{RF})$ intelligent classification algorithm.
3.1. Extraction of Image Features. Pictures in machine learning are usually stored in the form of ordered multiple dimensional matrices. If the storage matrices of the pictures are used as image features for various operations directly, the matrices will take up a lot of storage and computing resources, so it is necessary to extract the image features. The extracted image features can not only reduce the data dimension but also remove redundant information of the pictures and store important information of the pictures to improve the performance of intelligent classification.

3.1.1. Local Binary Patterns. LBP can describe the local texture features of an image and its advantages are rotation invariance and grayscale invariance. The calculation process of the LBP operator is shown in Figure 5(a): the gray value of the window center is used as the threshold value in a $3 \times 3$ window and the gray values of adjacent pixels are compared with it. The gray values of adjacent pixels are marked as 1 when it is greater than or equal to the threshold value; otherwise, it is 0 . Then, an 8-bit binary number is obtained clockwise and converted into a decimal number to obtain the LBP value of the window center pixel, and this LBP value can reflect the texture information of the area. The original LBP operator can only cover small areas with a fixed radius. In order to extract the texture features of different areas, the $3 \times 3$ window can be extended to any size and the square window can be replaced by a circular window. Figure 5(b) shows a $5 \times 5$ circular window and an LBP operator with 8 pixels in a circular area with a radius of 2 can be obtained [35]. Tis defined as the joint distribution of the gray levels of image pixels:

$$
T=t\left(g_{c}, g_{0}, g_{1}, \ldots, g_{p}\right),
$$

where $g_{c}$ is the gray value of the central blank point and $g_{p}$ is the gray value of the black point on the circumference. If the coordinates of $g_{c}$ are $(0,0)$, then the coordinates of $g_{p}$ are $[-R \sin (2 \pi / p), R \cos (2 \pi / p)]$, where $R$ is the radius and $p$ is a constant. The gray value of the point in the neighborhood that does not directly fall in the center of the pixel grid will be completed by linear interpolation. The gray value of the window point $g_{c}$ is set as the threshold and other pixels in the window are processed. The formula is defined as follows:

$$
\begin{aligned}
T & =t\left[s\left(g_{0}-g_{c}\right), s\left(g_{1}-g_{c}\right), \ldots, s\left(g_{p}-g_{c}\right)\right], \\
s(x) & = \begin{cases}1, & x>0, \\
0, & x \leq 0 .\end{cases}
\end{aligned}
$$

For the binary number obtained by formula (10), the LBP value of the window is obtained by calculating the weighted sum of pixels at different positions by formula (11):

$$
\mathrm{LBP}=\sum_{p=0}^{p-1} s\left(g_{p}-g_{c}\right) 2^{p} .
$$

However, the data dimension of LBP features extracted by this way is too large to be used as the input vectors of the intelligent classification algorithms directly, so the LBP 


\begin{tabular}{|c|c|c|c|c|c|c|}
\hline 180 & 52 & 5 & 1 & 0 & 0 & LBP value of \\
\hline 213 & 88 & 79 & 1 & & 0 & Binary: \\
\hline 158 & 87 & 156 & 1 & 0 & 1 & Decimal: 139 \\
\hline
\end{tabular}

(a)

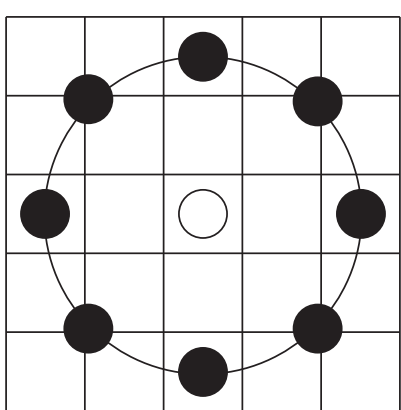

(b)

FIGURE 5: Extraction of LBP features: (a) original LBP operator; (b) improved LBP operator.

histogram is counted to be used as the input feature vectors. The LBP histogram divides the image into several regions and counts the number of occurrences of the LBP value in each region to form a composite vector.

3.1.2. Gray Level Cooccurrence Matrix. Although the improved LBP algorithm can describe the texture features of various regions, the lack of relevant calculation of the grayscale corresponding to the central pixel will bring difficulties to the subsequent fault classification. Therefore, the GLCM is used to extract the global texture features of the image to make up for the defects of the LBP algorithm. The GLCM not only contains the information such as direction, amplitude, and adjacent interval but also describes the statistical information of the grayscale, which can reflect the texture features of the image.

Any pixel $\left(x_{1}, y_{1}\right)$ in an image $f(x, y)$ is taken, then any other pixel $\left(x_{2}, y_{2}\right)$ is taken, and the expression for calculating the GLCM of various distances and angles is as follows [36]:

$$
Q(i, j, d, \theta)=\left\{\left(x_{1}, y_{1}\right),\left(x_{2}, y_{2}\right) \mid f\left(x_{1}, y_{1}\right)=i, f\left(x_{2} y_{2}\right)=j\right\},
$$

where $i$ and $j$ are the pixels of the image, $d$ is the distance between two pixels, and $\theta$ is the direction of the generation of GLCM. The texture features of the image are obtained by calculating the texture feature values of the GLCM, such as contrast, correlation, energy, and homogeneity.

3.2. Random Forest. RF is a classifier composed of many decision trees, but these decision trees are not related to each other. Random attribute is introduced in the training process of the decision trees, which makes the decision trees have better fault tolerance for the data samples. Therefore, $\mathrm{RF}$ has a good tolerance for outliers and is not prone to overfitting.

The principle of the RF classifier is shown in Figure 6. Firstly, after preprocessing the training samples, the training sets $S_{1}, \ldots, S_{i}, \ldots, S_{n}$ are generated randomly by the Bootstrap method. Next, the corresponding decision trees $T_{1}, \ldots, T_{i}, \ldots, T_{n}$ are generated through each training set. Then each decision tree is used to test the sample $X$ to obtain

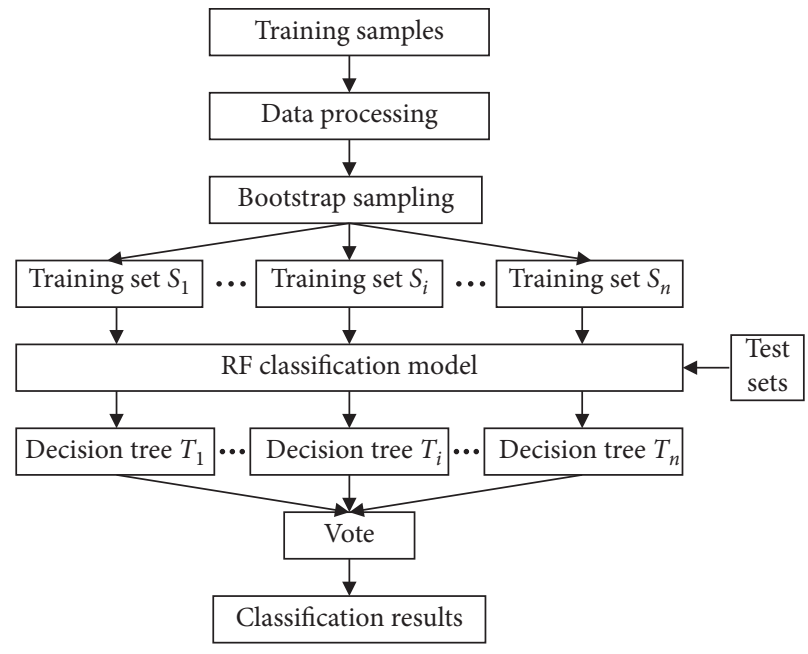

Figure 6: The principle of RF classifier.

the corresponding category $T_{1}(X), \ldots, T_{i}(X), \ldots, T_{n}(X)$. Finally, the most output category of decision trees is chosen as the category of test sample $X$ by voting.

\section{Experimental Testing}

4.1. Simulation Data Testing. In order to verify the effectiveness of the proposed method, this section uses Maxwell software to model the Y90S-4 motor and collects simulation data for the simulation experiment.

4.1.1. PVR of Healthy Motor. The finite element model of the motor is shown in Figure 7 and its parameters are shown in Table 1 . Then, the actual working conditions of the motor were simulated and the simulation experiment was carried out.

The three-phase currents under the rated load of the healthy motor model are shown in Figure 8(a). In order to show the three-phase currents clearly, only 200 milliseconds of data is intercepted in the figure. The waveform of the three-phase currents of the healthy motor is symmetrical, the amplitude is equal, and the phase difference is $120^{\circ}$ in turn. The PVA is used to analyze the three-phase currents under the rated load (the sampling frequency of the signal is 


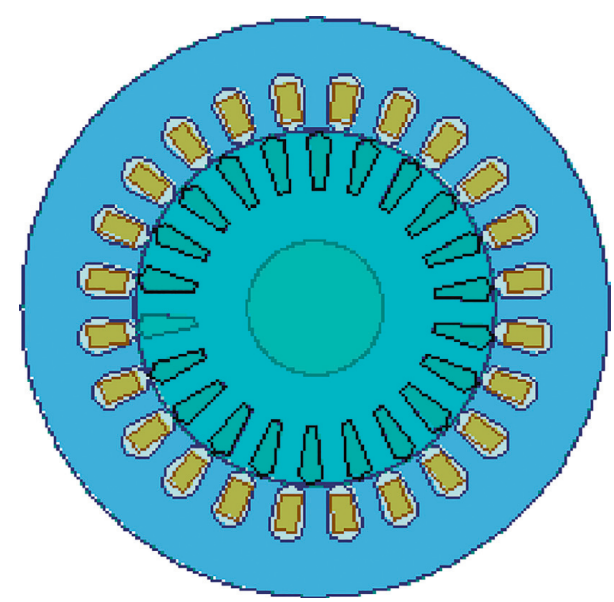

FIgURE 7: Finite element model of healthy motor.

TABle 1: Some design parameters of Y90S-4 IM.

\begin{tabular}{lc}
\hline Type & Parameter \\
\hline Power & $1.1 \mathrm{~kW}$ \\
Frequency & $50 \mathrm{~Hz}$ \\
Voltage & $380 \mathrm{~V}$ \\
Stator & 24 \\
Rotor & 22 \\
Length & $90 \mathrm{~mm}$ \\
Stator outer diameter & $130 \mathrm{~mm}$ \\
Stacking factor & 0.95 \\
Winding layers & 1 \\
Rotor outer diameter & $79.5 \mathrm{~mm}$ \\
Pole & 4 \\
Phase & 3 \\
Current & $2.8 \mathrm{~A}$ \\
Rated speed & $1400 \mathrm{rpm}$ \\
Skew width & 1 \\
Steel type & $\mathrm{D} 23 \_50$ \\
Stator inner diameter & $80 \mathrm{~mm}$ \\
Lamination sectors & 1 \\
Parallel branches & 1 \\
Rotor inner diameter & $30 \mathrm{~mm}$ \\
\hline
\end{tabular}

$1 \mathrm{kHz}$ and the data length is 1000); the result is plotted in the polar coordinate, as shown in Figure 8(b). When the motor is healthy, the PVR of the currents is a standard circle.

\subsubsection{PVR of Motor with Interturn Short-Circuit Fault.} The interturn short-circuit fault of the stator winding is caused by the destruction of the insulation between two or several adjacent turns in the winding. In order to simulate the interturn short-circuit fault in Maxwell software, an external circuit with a 10-turn interturn short-circuit fault of A-phase was built to provide control and excitation to the finite element model and the simulation experiment was carried out.

The waveform of the currents with a 10-turn interturn short-circuit fault of A-phase is shown in Figure 9(a). Compared with Figure 8(a), the three-phase currents are not balanced because of the interturn short-circuit fault in the A-phase winding and the amplitude of A-phase current is obviously larger than the other two phases [37]. The PVR of the currents with interturn short-circuit fault is shown in Figure 9(b). Compared with Figure 8(b), when the interturn short-circuit fault occurs in the motor, the negative sequence components of the three-phase currents lead to the unequal amplitudes of Park's vector components, which makes the PVR become an ellipse.

4.1.3. PVR of Motor with BRB Fault. The fractures of the rotor bars and the end ring are called the $\mathrm{BRB}$ fault collectively. When the BRB fault occurs in the motor, the current at the fracture cannot pass through normally. However, the broken part is not isolated from the whole rotor completely and there are other current paths between the rotor bars. Therefore, the current can be considered as not zero when establishing the BRB model, but its resistance is very large. So the conductivity of the broken bar was reduced greatly to establish the $\mathrm{BRB}$ model and the simulation experiment was carried out.

The waveform of the currents with 2 broken bars is shown in Figure 10(a). Compared with Figure 8(a), the BRB fault causes harmonic components at the frequencies of $(1 \pm 2 s) f_{1}$ in the currents and the frequency interval between the harmonic components and the fundamental component is very small. So the amplitude of the fundamental component is modulated and the currents have periodic fluctuations [38]. The PVR of the currents with two broken bars is shown in Figure 10(b). Compared with Figure 8(b), when the BRB fault occurs in the motor, the radius of the PVR fluctuates periodically because the harmonic components in the currents modulate the amplitudes of Park's vector components and a circular ring is formed.

4.1.4. Simulation Experiment Verification. According to the above modeling methods, healthy motor models, motor models with two broken bars' fault and 10-turn short-circuit fault of A-phase were built in Maxwell. The three-phase currents were obtained by simulating the motor models from 0.04 times of rated load to 1.2 times of rated load ( 0.04 times of rated load was increased each time). The PVA was used to analyze the three-phase currents and the results were plotted on the polar coordinates to form $30 \times 3$ groups of image samples (the size of each picture was unified to $256 \times 256$ pixels).

The LBP algorithm was used to extract the image features of $30 \times 3$ groups of PVRs. In the extraction process, the window size was $5 \times 5$, the radius was 2 , the pixel was 8 , the area size was $4 \times 4$, and the dimension of the LBP histogram of each region was 59 . Therefore, $4 \times 4 \times 59=944$-dimensional feature vectors of LBP histogram in an image were obtained. For GLCM features, $d$ was taken from 1 to 10 and the four texture feature values of contrast, correlation, energy, and homogeneity were taken from the GLCM of $0^{\circ}, 45^{\circ}$, $90^{\circ}$, and $135^{\circ}$, respectively. The mean value and mean square deviation of the same eigenvalue of 4 angles were taken as feature vectors, a total of 8 -dimensional vectors. The data dimension of the two features is 1024 in total; although this 


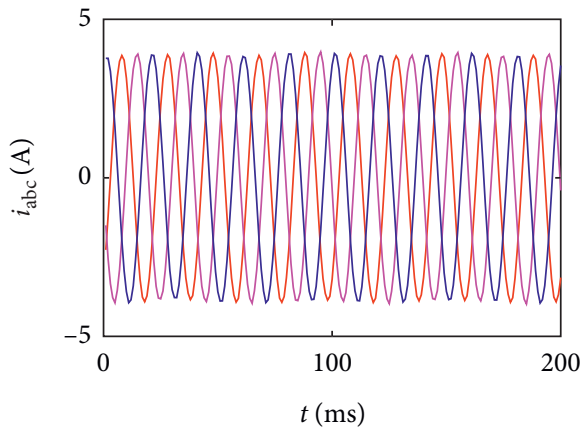

(a)

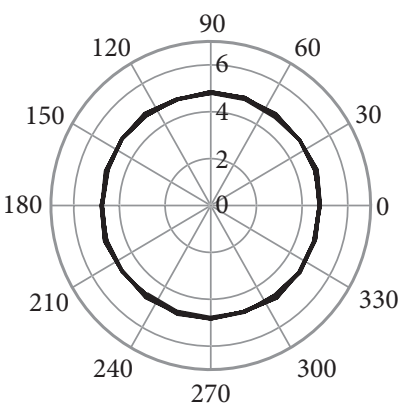

(b)

FIgure 8: Healthy motor model: (a) current; (b) PVR.

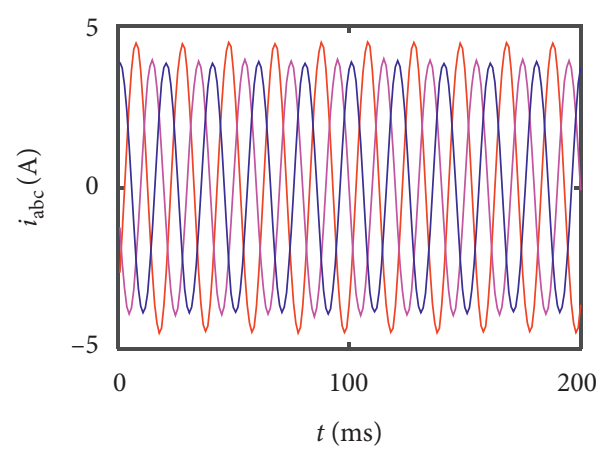

(a)

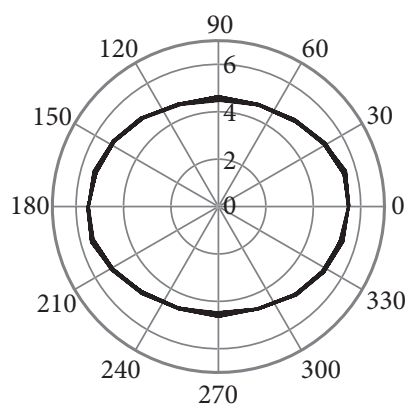

(b)

FIGURE 9: Motor model with interturn short-circuit fault: (a) current; (b) PVR.

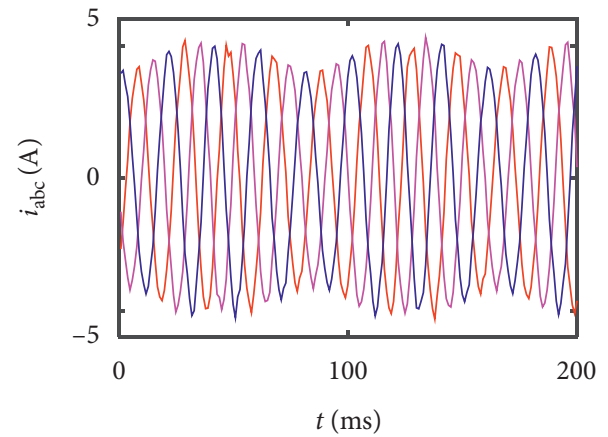

(a)

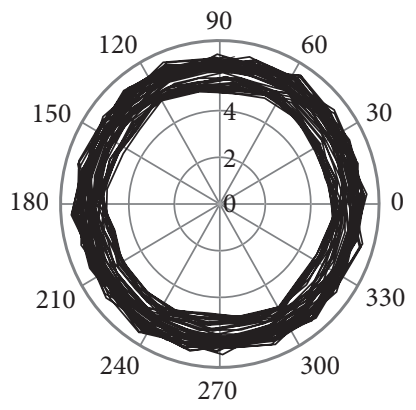

(b)

FIgure 10: Motor model with BRB fault: (a) current; (b) PVR.

dimension is not small, it is 64 times smaller than the 65536 dimensions of the original image.

The LBP features of the PVRs with the rated load are shown in Figure 11. It can be seen from the figure that the LBP features show the texture features of the PVRs accurately. The gray values of the blank part inside and outside the ring are all the same, so the LBP features extracted from this part are also the same and remain blank. While the gray values around the ring are different and the extracted LBP features are also different. The LBP features of the healthy motor are shown in Figure 11(a), the distribution of the texture features at this time is consistent with the PVR, which has circular regularity. The LBP features of two broken bars are shown in Figure 11(b), the distribution of the texture features also has a circular regularity, but the thickness of the distribution is increased significantly compared with Figure 11(a). The LBP features of 10-turn short-circuit fault of A-phase are shown in Figure 11(c); the distribution of the texture features under this fault is obviously different from that in Figures 11(a) and 11(b) and has an elliptical regularity. When the motor is healthy, the thickness and diameter of the PVR are 8 pixels and 151 pixels, respectively. The thickness of the PVR of two broken bars is 31 pixels and the long axis of the PVR is 167 pixels 


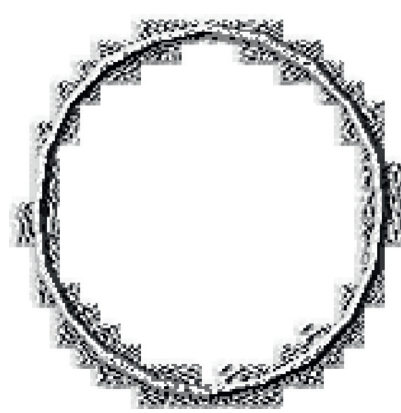

(a)

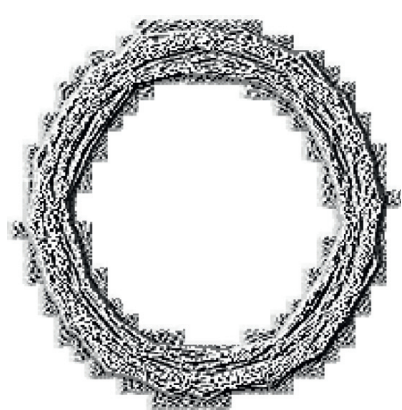

(b)

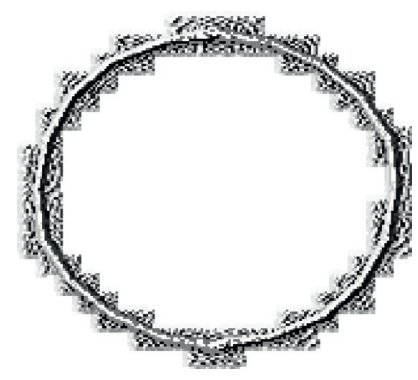

(c)

FIgURE 11: LBP features of the PVRs: (a) healthy motor, (b) two broken bars, and (c) 10-turn short-circuit fault of A-phase.

when the motor has interturn short-circuit fault. The thickness, diameter, and major axis of the LBP feature in the three states are all 5 pixels more than the original image, which is due to the characteristics of the LBP algorithm.

$20 \times 3$ groups of images in the image samples were selected as training samples and the remaining $10 \times 3$ groups of images were used as test samples. The LBP and GLCM features of the training samples were used as the input vectors of RF to train the classification model of motor faults. When a test sample was classified, the voting method with decision trees was adopted and the category with the largest number of votes was taken as the category of the test sample. The trained RF fault classifier was used to identify the test samples and the results are shown in Figure 12.

It can be seen from Figure 12 that the fault identification method of the motor based on machine vision can identify the fault types of all test samples accurately. The accuracy rate is as high as $100 \%$, which verifies the feasibility and superiority of the proposed method definitely.

4.2. Actual Data Testing. The physical experiment was carried out to further analyze the performance of the proposed method. The experimental platform is shown in Figure 13.

The experimental motor is Y90S-4 IM and the load is FZ25 J magnetic powder brake. The torque can be adjusted by changing the excitation current linearly to meet the needs of different working conditions. At the same time, in order to carry out the fault motor experiment, a rotor with 2 broken bars and a multitap stator winding are equipped, as shown in Figures 14(a) and 14(b), respectively. The multitap terminals of the A-phase winding can simulate different degrees of interturn short-circuit faults through different wiring methods.

The physical experiment is similar to the simulation experiment, mainly for the healthy motor, the motor with two broken bars, and a 10-turn interturn short-circuit fault of A-phase. The three-phase currents of three kinds of motors under different loads are collected and the sampling frequency and data length are consistent with the simulation experiment.

The PVA was used to analyze the three-phase currents and the results were plotted on the polar coordinates to form $24 \times 3$ groups of image samples (the size of each picture was

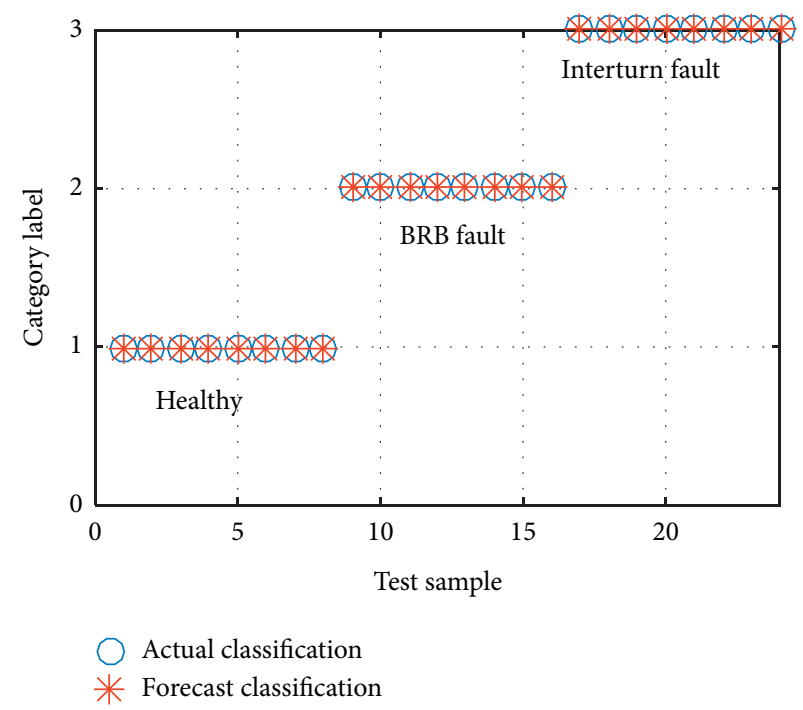

FIGURE 12: Fault identification results of simulation motor.

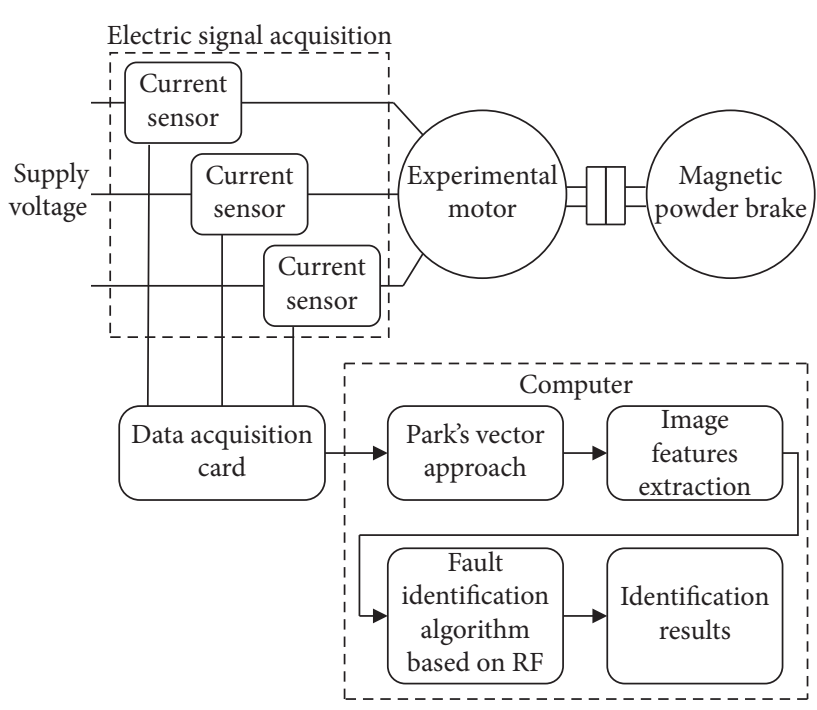

FIGURE 13: Structure diagram of the experimental platform.

unified to $256 \times 256$ pixels). The PVRs of the motor currents under rated load are shown in Figure 15. These PVRs show different shapes at different faults, which are consistent with 


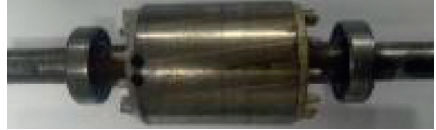

(a)

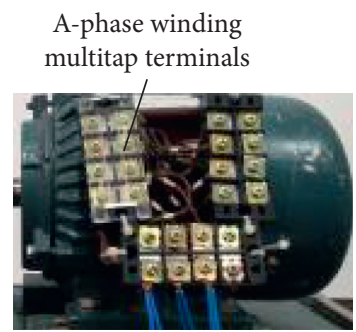

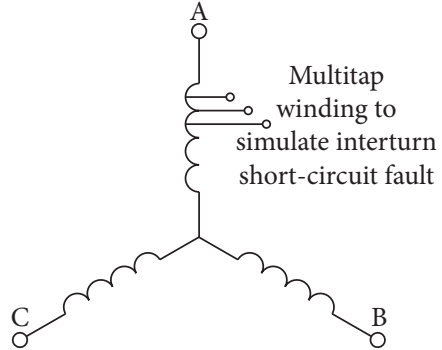

(b)

FIGURE 14: Sator and rotor faults: (a) two broken bars; (b) 10-turn interturn short-circuit fault.

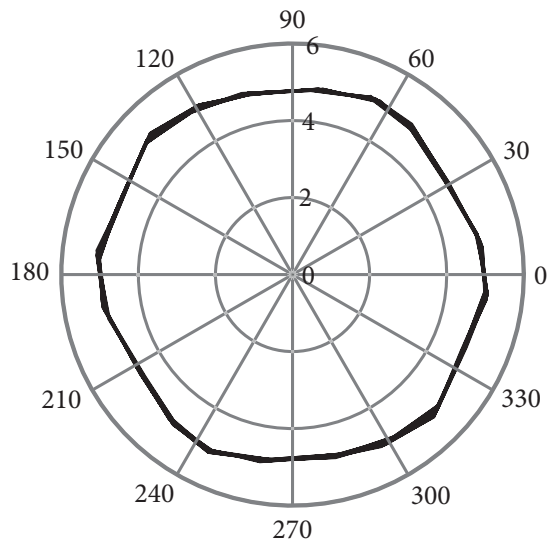

(a)

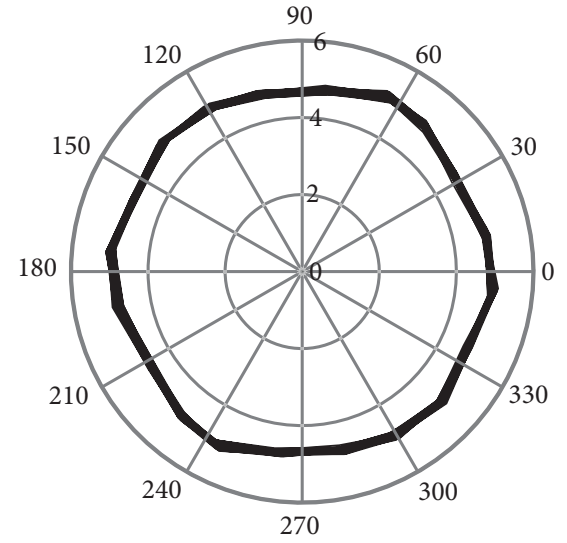

(b)

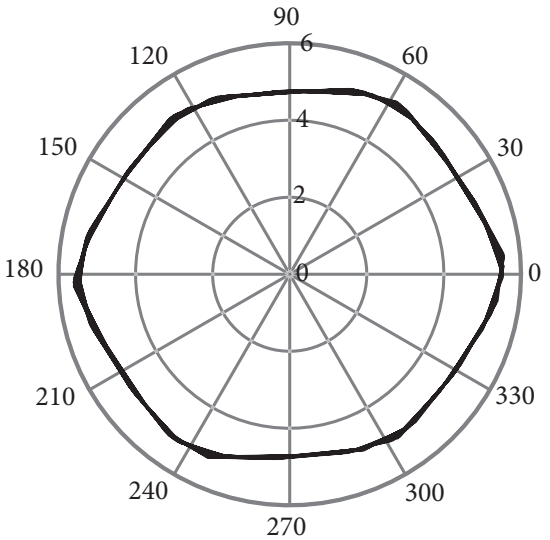

(c)

FIGURE 15: PVRs of actual motor: (a) healthy motor, (b) two broken bars, and (c) 10-turn short-circuit fault of A-phase.

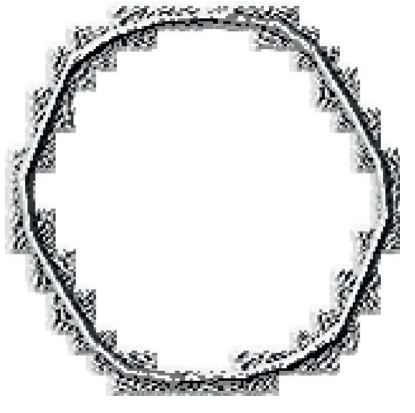

(a)

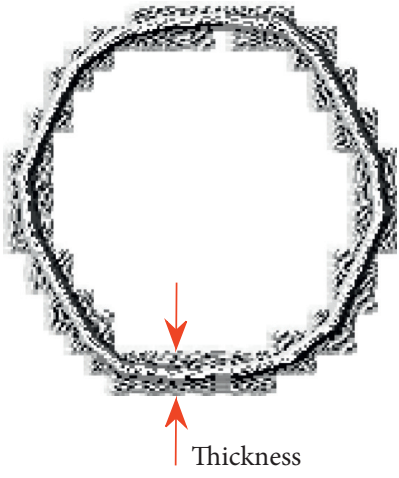

(b)

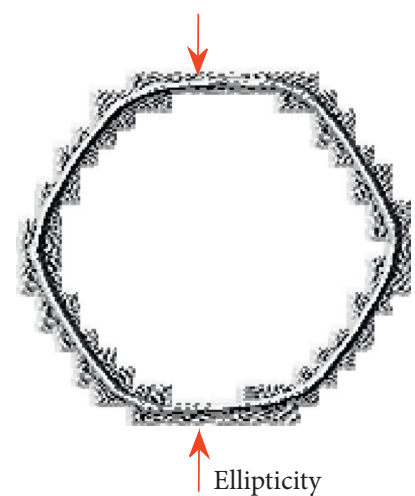

(c)

Figure 16: LBP features of the PVRs: (a) healthy motor, (b) two broken bars, and (c) 10-turn short-circuit fault of A-phase.

the conclusions of the simulation experiment. However, the PVRs of the actual motor are not round enough and can only be close to circles or ellipses because the manufacturing process of the motor is not perfect and the supply voltage is not a standard sine wave.

The LBP algorithm was used to extract the image features of $24 \times 3$ groups of PVRs and the parameters were consistent with Section 4.1.4. The LBP features of PVRs of the actual motor under rated load are shown in Figure 16. The texture features distribution of the healthy motor is shown in Figure 16(a), which is close to circle. The texture feature distribution of two broken bars is shown in Figure 16(b), which is close to circle too, but the thickness of the distribution is increased compared with the healthy motor. The LBP features of 10-turn short-circuit fault of A-phase are shown in Figure 16(c); the distribution of the texture features under this fault is close to ellipse. When the motor is healthy, the thickness and diameter of the PVR are 7 pixels 


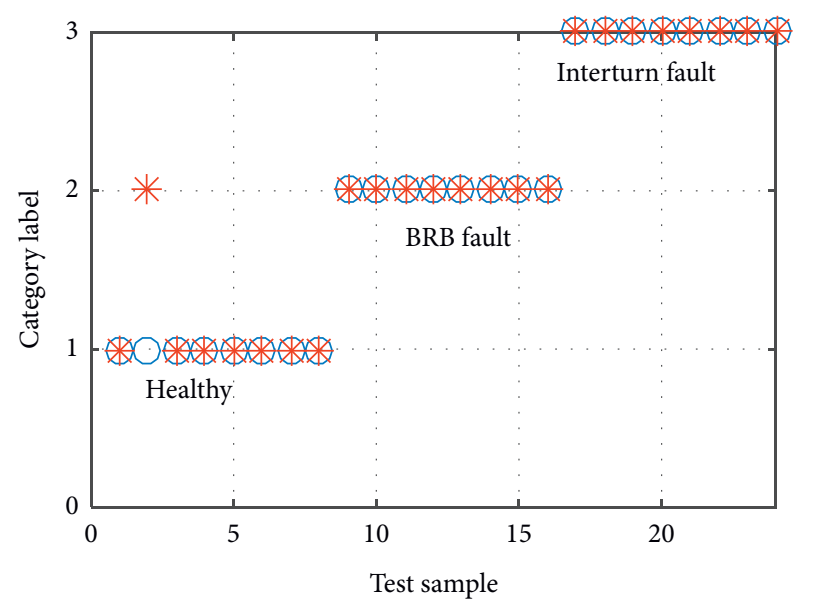

Actual classification

* Forecast classification

FIGURE 17: Fault identification results of actual motor.

and 156 pixels, respectively. The thickness of the PVR of two broken bars is 16 pixels and the long axis of the PVR is 167 pixels when the motor has interturn short-circuit fault. The thickness, diameter, and major axis of the LBP feature in the three states are all 5 pixels more than the original image, which is due to the characteristics of the LBP algorithm. However, the LBP features of PVRs are similar to each other because the discrimination of PVRs of three kinds of motors is not obvious enough, which increases the difficulty of subsequent RF classification.

$16 \times 3$ groups of LBP and GLCM features of the image samples were selected as training samples and the remaining $8 \times 3$ groups were used as test samples. The training samples were used to train the RF classifier to obtain the classification model of motor faults and the test samples were used to test the performance of the classification model. The test results are shown in Figure 17.

It can be seen from Figure 17 that the fault identification method of IM based on machine vision still has a high accuracy rate for the actual motor. The amplitudes of the three-phase stator currents and slip rate of the motor are small when the motor is under light load and the modulation effect on the amplitudes of Park's vector components is not obvious. So the PVRs of intact and broken bars are relatively close, the extracted image features are also similar, and the samples are insufficient, which leads to a classification error of the test samples. But the overall accuracy rate is still as high as $95.83 \%$, which further verifies the effectiveness of the proposed method.

\section{Conclusions}

This paper proposes a fault identification method of IMs based on machine vision by combining signal processing with artificial intelligence, which solves the problem of manual analysis and identification of detection results in the fault detection method based on signal processing. The results of the simulation and physical experiments show that the proposed method can identify the broken bars and interturn short-circuit fault of IMs effectively. Although the number of samples is small, the accuracy is still as high as $100 \%$ (simulation experiment) and 95.83\% (physical experiment), which provides a new method for automatic identification of induction motor faults. However, the drawback is that the proposed method has the same limitations as the data-driven methods. The fault data is not easy to obtain, which leads to a decrease in the accuracy of the proposed method. The future work is going to realize fault classification and identification based on the combination of data-driven methods and logical reasoning methods.

\section{Data Availability}

The data used to support the findings of this study are available from the corresponding author upon request.

\section{Conflicts of Interest}

The authors declare no conflicts of interest.

\section{Acknowledgments}

This work was supported by China Coal Technology Engineering Group (Grant no. 2020-TD-QN002).

\section{References}

[1] J. Lu, P. Wang, S. Duan, L. Shi, and L. Han, "Detection of broken rotor bars fault in induction motors by using an improved MUSIC and least-squares amplitude estimation," Mathematical Problems in Engineering, vol. 2018, Article ID 5942890, 12 pages, 2018.

[2] Y. H. Liu, J. W. Qiao, D. Y. Huo et al., "Development of mineused flameproof three-phase asynchronous motor with high voltage and high efficiency," Industry and Mine Automation, vol. 43, no. 7, pp. 32-36, 2017.

[3] X. Sun, M. Wu, G. Lei, Y. Guo, and J. Zhu, "An improved model predictive current control for PMSM drives based on current track circle," IEEE Transactions on Industrial Electronics, p. 1, 2020.

[4] X. Sun, L. Chen, Z. Yang, and H. Zhu, "Speed-sensorless vector control of a bearingless induction motor with artificial neural network inverse speed observer," IEEE/ASME Transactions on Mechatronics, vol. 18, no. 4, pp. 1357-1366, 2013.

[5] X. Sun, C. Hu, G. Lei, Y. Guo, and J. Zhu, "State feedback control for a PM hub motor based on gray wolf optimization algorithm," IEEE Transactions on Power Electronics, vol. 35, no. 1, pp. 1136-1146, 2020.

[6] G. D. Cheng, H. P. Wang, and J. J. Xia, "Study on rotor-side frequency conversion speed regulation technology for high voltage wound-rotor motor," Industry and Mine Automation, vol. 44, no. 8, pp. 81-86, 2018.

[7] Y. Xie, X. T. Shan, J. P. Guo et al., "The relationship study between field changes and faulty condition in squirrel-cage induction motor with broken bars fault," in Proceedings of the CSEE, vol. 37, no. 14, pp. 4222-4231, 2017.

[8] C. J. Aileen, S. Nagarajan, and S. R. Reddy, "Detection of broken bars in three phase squirrel cage induction motor using finite element method," in Proceedings of the International Conference on Emerging Trends in Electrical and 
Computer Technology, pp. 249-254, Nagercoil, India, March 2011.

[9] V. Climente-Alarcon, A. Arkkio, and J. Antonino-Daviu, "2D magnetomechanical transient study of a motor suffering a bar breakage," IEEE Transactions on Industry Applications, vol. 54, no. 3, pp. 2097-2104, 2018.

[10] P. A. Panagiotou, I. Arvanitakis, N. Lophitis, J. A. AntoninoDaviu, and K. N. Gyftakis, "FEM approach for diagnosis of induction machines' non-adjacent broken rotor bars by shorttime Fourier transform spectrogram," The Journal of Engineering, vol. 2019, no. 17, pp. 4566-4570, 2019.

[11] Y. G. Lv, W. Y. Zhang, and J. C. Liu, "Analysis and diagnosis of broken rotor bars in induction motors based on Maxwell," in Proceedings of the 33rd Chinese Control Conference, pp. 3065-3069, Nanjing, China, July 2014.

[12] N. Lahouasnia, M. F. Rachedi, and T. Deghboudj, "Detection of broken rotor bar defect in squirrel cage induction machine," in Proceedings of the 2019 International Conference on Advanced Electrical Engineering, pp. 1-5, Algiers, Algeria, November 2019.

[13] A. V. J. S. Praneeth, N. V. Anand, K. S. Sandhu et al., "Analysis and modeling of three winding stator interturn fault on induction machine for electric vehicle application," in Proceedings of the 2018 IEEE International Conference on Power Electronics, Drives and Energy Systems, pp. 1-6, Chennai, India, December 2018.

[14] S. Duvvuri, "Modeling and simulation of slip-ring induction motors with stator and rotor inter-turn faults for diagnostics," in Proceedings of the 2018 8th IEEE India International Conference on Power Electronics, pp. 1-5, Jaipur, India, December 2018.

[15] G. D. Yuchechen, M. A. Mazzoletti, and G. R. Bossio, "Effects of stator winding interturn short-circuit faults of the IM by using intantaneous power theory," in Proceedings of the 2018 Argentine Conference on Automatic Control, pp. 1-6, Buenos Aires, Argentina, November 2018.

[16] D. C. Patel and M. C. Chandorkar, "Modeling and analysis of stator interturn fault location effects on induction machines," IEEE Transactions on Industrial Electronics, vol. 61, no. 9, pp. 4552-4564, 2014.

[17] W. Sun, R. Zhao, R. Yan, S. Shao, and X. Chen, "Convolutional discriminative feature learning for induction motor fault diagnosis," IEEE Transactions on Industrial Informatics, vol. 13, no. 3, pp. 1350-1359, 2017.

[18] M. R. Barusu, U. Sethurajan, and M. Deivasigamani, "Noninvasive method for rotor bar fault diagnosis in three-phase squirrel cage induction motor with advanced signal processing technique," The Journal of Engineering, vol. 2019, no. 17, pp. 4415-4419, 2019.

[19] A. Naha, A. K. Samanta, A. Routray, and A. K. Deb, “A method for detecting half-broken rotor bar in lightly loaded induction motors using current," IEEE Transactions on Instrumentation and Measurement, vol. 65, no. 7, pp. 1614-1625, 2016.

[20] J. R. Magdaleno, H. P. Barreto, J. R. Cortes et al., "Hilbert spectrum analysis of induction motors for the detection of incipient broken rotor bars," Measurement, vol. 109, pp. 247-255, 2017.

[21] P. P. Wang, X. X. Chen, Y. Zhang et al., "IBPSO-based MUSIC algorithm for broken rotor bars fault detection of induction motors," Chinese Journal of Mechanical Engineering, vol. 31, no. 1, pp. 41-50, 2018.

[22] D. C. Martinez, R. O. Rios, R. J. R. Troncoso et al., "Fused empirical mode decomposition and MUSIC algorithms for detecting multiple combined faults in induction motors," Journal of Applied Research and Technology, vol. 10, no. 1, pp. 160-167, 2015.

[23] P.-P. Wang, Q. Yu, Y.-J. Hu, and C.-X. Miao, "Online detection of broken rotor bar fault in induction motors by combining estimation of signal parameters via min-norm algorithm and least square method," Chinese Journal of Mechanical Engineering, vol. 30, no. 6, pp. 1285-1295, 2017.

[24] K. N. Gyftakis, A. J. Marques Cardoso, and J. A. AntoninoDaviu, "Introducing the filtered Park's and filtered extended Park's vector approach to detect broken rotor bars in induction motors independently from the rotor slots number," Mechanical Systems and Signal Processing, vol. 93, pp. 30-50, 2017.

[25] M. Sahraoui, A. Ghoggal, S. Guedidi, and S. E. Zouzou, "Detection of inter-turn short-circuit in induction motors using Park-Hilbert method," International Journal of System Assurance Engineering and Management, vol. 5, no. 3, pp. 337-351, 2014.

[26] V. F. Pires, D. Foito, J. Martins et al., "Detection of stator winding fault in induction motors using a motor square current signature analysis (MSCSA)," in Proceedings of the IEEE International Conference on Power Engineering Energy and Electrical Drives, pp. 507-512, Riga, Latvia, May 2015.

[27] M. h. Drif and A. J. M. Cardoso, "stator fault diagnostics in squirrel cage three-phase induction motor drives using the instantaneous active and reactive power signature analyses," IEEE Transactions on Industrial Informatics, vol. 10, no. 2, pp. 1348-1360, 2014.

[28] R. Sharifi and M. Ebrahimi, "Detection of stator winding faults in induction motors using three-phase current monitoring," ISA Transactions, vol. 50, no. 1, pp. 14-20, 2011.

[29] E. M. T. Eldin, H. R. Emara, E. M. Aboul-Zahab, and S. S. Refaat, "Monitoring and diagnosis of external faults in three phase induction motors using artificial neural network," in Proceedings of the IEEE Power Engineering Society General Meeting, pp. 1-7, Tampa, FL, USA, June 2007.

[30] B. Bessam, A. Menacer, M. Boumehraz, and H. Cherif, "Detection of broken rotor bar faults in induction motor at low load using neural network," ISA Transactions, vol. 64, pp. 241-246, 2016.

[31] A. Jawadekar, S. Paraskar, S. Jadhav, and G. Dhole, "Artificial neural network-based induction motor fault classifier using continuous wavelet transform," Systems Science \& Control Engineering, vol. 2, no. 1, pp. 684-690, 2014.

[32] D. A. Asfani, A. K. Muhammad, M. H. Syafaruddin, M. H. Purnomo, and T. Hiyama, "Temporary short circuit detection in induction motor winding using combination of wavelet transform and neural network," Expert Systems with Applications, vol. 39, no. 5, pp. 5367-5375, 2012.

[33] P. Gangsar and R. Tiwari, "A support vector machine based fault diagnostics of Induction motors for practical situation of multi-sensor limited data case," Measurement, vol. 135, pp. 694-711, 2019.

[34] R. J. Romero, R. Saucedo, E. Cabal et al., "FPGA-based online detection of multiple combined faults in induction motors through information entropy and fuzzy inference," IEEE Transactions on Industrial Electronics, vol. 58, no. 11, pp. 5263-5270, 2011.

[35] Z. Guo, X. Wang, J. Zhou, and J. You, "Robust texture image representation by scale selective local binary patterns," IEEE Transactions on Image Processing, vol. 25, no. 2, pp. 687-699, 2016. 
[36] G. Zheng, X. Li, L. Zhou et al., "Development of a gray-level Co-occurrence matrix-based texture orientation estimation method and its application in sea surface wind direction retrieval from SAR imagery," IEEE Transactions on Geoscience and Remote Sensing, vol. 56, no. 9, pp. 5244-5260, 2018.

[37] N. P. Kumar and T. B. Isha, "FEM based electromagnetic signature analysis of winding inter-turn short-circuit fault in inverter fed induction motor," CES Transactions on Electrical Machines and Systems, vol. 3, no. 3, pp. 309-315, 2019.

[38] P. Wang, J. Lu, L. Shi, Y. Zhang, Z. Tong, and N. Wang, "Method for extracting current envelope for broken rotor bar fault detection of induction motors at time-varying loads," IET Electric Power Applications, vol. 14, no. 6, pp. 1067-1077, 2020. 